\title{
COMMENT Telemedicine for treating mental health and substance use disorders: reflections since the pandemic
}

\author{
Neuropsychopharmacology (2021) 46:1068-1070; https://doi.org/10.1038/s41386-021-00960-4
}

\section{INTRODUCTION}

Since the United States COVID-19 pandemic emergency began, telemedicine use has accelerated [1]. Prior to the pandemic, mental health and/or substance use disorder (MH/SUD) care delivered by telemedicine had been increasing but infrequently used-in fewer than $1 \%$ of visits $[2,3]$. In contrast, in early October $2020,41 \%$ of $\mathrm{MH} / \mathrm{SUD}$ visits were conducted via telemedicine [4]. The rapid increase in telemedicine during the pandemic was enabled by sweeping temporary changes in federal and state regulations and health plan reimbursement policies that reduced longstanding barriers. These changes included federal relaxation of HIPAA compliance for telemedicine, removal of the requirement for an initial in-person appointment to prescribe buprenorphine (prohibited under the Ryan Haight Act), Medicare coverage for audioonly telephone visits, and an expanded list of services and types of providers who could deliver telemedicine. Other changes included expanding Medicaid telemedicine coverage policies, requiring commercial insurance parity for in-person versus telemedicine visits, and states allowing out-of-state providers to deliver care [1, 5-7]. Additionally, some commercial insurers voluntarily expanded telemedicine coverage. While the transition to virtual care occurred quickly $[8,9]$, it is important to take stock of these recent advances as well as continuing challenges. In this Commentary, we briefly describe our transition to telemedicine at McLean Hospital and elaborate on the national health policy and public health context that should inform our thinking on the role of telemedicine in MH/SUD care post-pandemic.

McLean is a psychiatric hospital near Boston, Massachusetts that is part of the Mass General Brigham health system. McLean provides inpatient, residential, partial hospital, and outpatient care for individuals with mental health and substance use disorders; in fiscal year 2019 there were over 45,000 outpatient visits. On March 16, 2020, several days after the governor of Massachusetts declared a state public health emergency, McLean discontinued in-person care for outpatients; the transition to telemedicine video services, which previously had not been used at McLean, occurred within 2 weeks. Outpatient encounters initially decreased during the March transition but by April 2020 rebounded to a similar volume as pre-pandemic (Fig. 1). Video visits predominated and the proportion of phone visits decreased over time.

\section{HEALTH POLICY AND PUBLIC HEALTH CONSIDERATIONS FOR THE USE OF TELEMEDICINE POST-PANDEMIC}

Similar to our experience, recent research also finds that nationally telemedicine is playing an important role in preserving MH/SUD care during the pandemic; despite that, there have been some disruptions observed in MH/SUD care $[4,8,10,11]$.

While more research is needed to clarify the patient and systems factors associated with more versus less successful transitions to telemedicine, findings of some care disruption despite rapid telemedicine deployment in MH/SUD care are an important observation. This is because an often stated policy goal of telemedicine is to improve access to care, particularly for patients who lack geographic access to clinicians qualified to treat their illness-for example, rural patients $[12,13]$. Furthermore, MH/SUDs are considered to be particularly amenable to care via telemedicine, relative to other health care conditions; for example, earlier research on the diffusion of telemedicine in Medicare found that nearly $80 \%$ of telemedicine visits were for mental health conditions [14]. However, there are some patients for whom the use of telemedicine, particularly video visits, poses significant barriers. The "digital divide" affects many patients who are in groups that are already underserved-such as racial or ethnic minorities, those in poverty, and the elderly [15-17]. Recent evidence suggests disparities in receiving MH/SUD care during the pandemic for individuals from these groups [8]. Addressing the digital divide will require a range of solutions to address deficits in community broadband availability, patient access to affordable devices and adequate privacy, assisting patients with digital literacy, health care providers/organizations employing digital solutions that are userfriendly for patients of varying cognitive and physical capabilities, and clinicians overcoming patient mistrust of technology [18].

Additionally, while many patients find telemedicine an adequate or even preferable alternative for in-person care, not all do [19]. There are some clinical characteristics for which in-person care, or a hybrid of in-person and telemedicine visits, would be better for the patient. For example, patients struggling with isolation may be better served by leaving their home to attend treatment. Furthermore, while meta-analyses describe telemedicine's effectiveness for depressive and anxiety disorders [20, 21], there is less evidence for SUDs [22] or schizophrenia [23]. Also lacking is a systematic understanding of effectiveness of certain aspects of clinical care via telemedicine compared to in-person care, such as elements of the mental status exam (e.g., evaluating eye contact); and the experience of virtual group therapy warrants additional research. These gaps will be important to resolve as we think about the role of telemedicine across varied diagnostic populations, post-pandemic.

Additionally, there are clinician-specific factors hindering access to care via telemedicine. Even in non-rural areas, there are shortages of clinicians with specialty MH/SUD expertise [24], and even fewer who accept insurance [25]. The well-documented shortage of specialty clinicians has been an impetus to finding alternative delivery models, such as collaborative care with primary care and digital health to assist in the treatment of patients with milder conditions [26, 27]. Widespread clinician shortages in many communities may limit the success telemedicine can have in improving geographical access to care. This is particularly relevant for patients who require specialized teambased behavioral health care unavailable in their state, due to complex clinician-specific state licensing and prescribing 

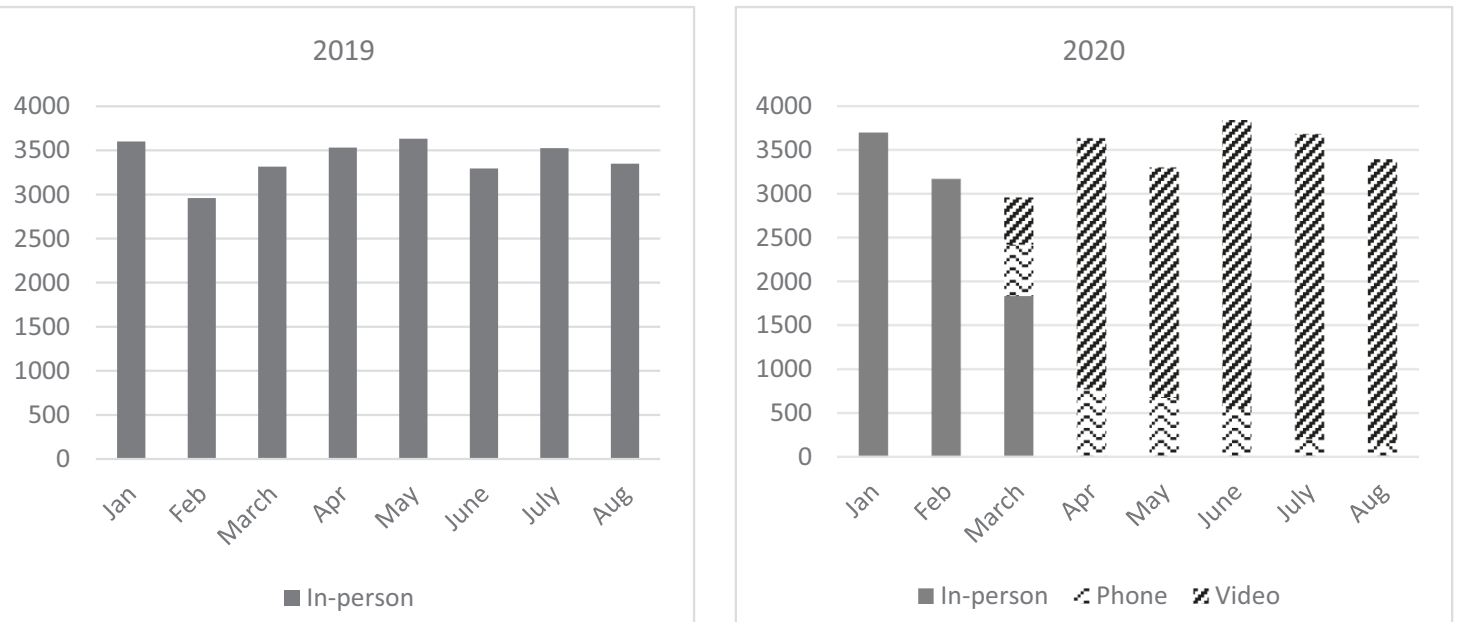

Fig. 1 Monthly volume of behavioral health outpatient encounters January-August, 2019 and 2020. In-person outpatient care discontinued in March 2020, corresponding to a decrease in total encounters that month, relative to March 2019. The transition to telemedicine, largely video visits, was rapid--by April 2020 outpatient visit volume was similar to pre-pandemic levels. Initially post-pandemic, phone visits were more common, but decreased over time and were replaced by video visits.

regulations. While many state restrictions have eased during the pandemic [7], the complex licensing requirements for out-of-state team-based care remains a barrier.

Provider and patient barriers notwithstanding, telemedicine can offer options for individuals whose life circumstances make inperson treatment difficult, such as patients who are caregivers of children or others, and those who find it difficult to leave the house due to physical or psychological challenges. Many patients' work schedules make the logistics of in-person care challenging. For these patients, telemedicine could enable initiation and continuation of care. The National Household Survey on Drug Use and Health documents that only about $10 \%$ of patients with a SUD receive treatment [28]. In 2018, the National Center for Quality Assurance reported that only $27-43 \%$ of patients hospitalized for a mental illness had follow-up within 7 days of discharge-and these rates are getting lower each year [29]. Tools that can help us improve these statistics would be most welcome. Telemedicine, if payers continue reimbursement commensurate with in-person treatment, could be a tool that can help us to move the needle in the right direction.

We should consider telemedicine as we do any of our other therapeutic tools. There is no one treatment in psychiatry (or, arguably in all of medicine) that works well for every person who suffers with a particular disorder. For example, some patients will need medication, some psychotherapy, and some both. A particular medication may work for some patients but be ineffective or have intolerable side effects for others. All of our therapeutic trials and decisions are made in concert with patients, taking into consideration their preferences, needs, and individual circumstances.

As policy-makers and health insurers consider the role that telemedicine should play in MH/SUD care during and after the pandemic, it will be important to consider that it is a valuable tool that can improve access to care-including for those who are constrained by circumstance-but not a panacea. That is, telemedicine will not solve the longstanding problems of an inadequate supply of clinicians who can provide MH/SUD care and, absent focused efforts by policy-makers and health care organizations, it may disproportionately leave behind some traditionally underserved and vulnerable populations.

\section{FUNDING AND DISCLOSURE}

We gratefully acknowledge funding from the NIMH (R01MH112829, ABB) and NIDA (R01DA048533, P30 DA035772, $A B B$ and SFG; and K23DA050780, DES). The authors declare no competing interests.

\section{ACKNOWLEDGEMENTS}

We thank Elizabeth Fox for analyzing the electronic health record data to provide the outpatient encounter volumes.

\section{AUTHOR CONTRIBUTIONS}

$A B B, D E S$, LEH, and SFG conceptualized the overall framework of the Comment content. $A B B$ drafted the first draft; $A B B, D E S, L E H$, and SFG revised it critically for important intellectual content and provided final approval of the version to be published. $A B B$ is accountable for all aspects of the work in ensuring that questions related to the accuracy or integrity of any part of the work are appropriately investigated and resolved.

\section{ADDITIONAL INFORMATION}

Publisher's note Springer Nature remains neutral with regard to jurisdictional claims in published maps and institutional affiliations.

Alisa B. Busch (iD $^{1,2,3}$, Dawn E. Sugarman ${ }^{1,2}$, Lisa E. Horvitz ${ }^{1}$ and Shelly F. Greenfield ${ }^{1,2}$

${ }^{1}$ McLean Hospital, Belmont, MA, USA; ${ }^{2}$ Department of Psychiatry, Harvard Medical School, Boston, MA, USA and ${ }^{3}$ Department of Health Care Policy, Harvard Medical School, Boston, MA, USA Correspondence: Alisa B. Busch (abusch@mclean.harvard.edu)

\section{REFERENCES}

1. Bosworth A, Ruhter J, Samson LW, Sheingold S, Taplin C, Tarazi W, et al. Mediciare beneficiary use of telehealth vistis: early data from the start of the COVID-19 pandemic. Washington, DC: Office of the Assistant Secretary for Planning and Evaluation, Department of Health and Human Services; 2020.

2. Huskamp HA, Busch AB, Souza J, Uscher-Pines L, Rose S, Wilcock A, et al. How is telemedicine being used in opioid and other substance use disorder treatment? Health Aff. 2018;37:1940-7.

3. Patel SY, Huskamp HA, Busch AB, Mehrotra A. Telemental health and US ruralurban differences in specialty mental health use, 2010-2017. Am J Public Health. 2020;110:1308-14.

4. Mehrotra A, Chernew M, Linetsky D, Hatch H, Cutler D, Schneider EC. The impact of the COVID-19 pandemic on outpatient care: visits return to prepandemic levels, but not for all providers and patients. 2020. Commonwealth Fund. https:// doi.org/10.26099/41xy-9m57. Accessed 20 Oct 2020.

5. Telehealth: Delivering Care Safely During COVID-19. US Department of Health and Human Services; 2020. https://www.hhs.gov/coronavirus/telehealth/index. html. Accessed 10 Dec 2020.

6. Weigel G, Ramaswamy A, Sobel L, Salganicoff A, Cubanski J, Freed M. Opportunities and barriers for telemedicine in the U.S. during the COVID-19 emergency and beyond. Kaiser Family Foundation; 2020. https://www.kff.org/womens- 
1070

health-policy/issue-brief/opportunities-and-barriers-for-telemedicine-in-the-u-sduring-the-covid-19-emergency-and-beyond/. Accessed 24 Sept 2020.

7. Center for Connected Health Policy. COVID-19 related state actions. https://www. cchpca.org. Accessed 10 Sept 2020

8. Yang J, Landrum MB, Zhou L, Busch AB. Disparities in outpatient visits for mental health and/or substance use disorders during the COVID-19 surge and partial reopening in Massachusetts. Gen Hospital Psychiatry. 2020;67:100-6.

9. Mehrotra A. The impact of the COVID-19 pandemic on outpatient visits: a rebound emerges. To the Point (blog): Commonwealth Fund; 2020. https://doi. org/10.26099/ds9e-jm36.

10. Uscher-Pines L, Sousa J, Raja P, Mehrotra A, Barnett M, Huskamp HA. Suddenly becoming a "Virtual Doctor": experiences of psychiatrists transitioning to telemedicine durin the COVID-19 pandemic. Psychiatr Serv. 2020;71:1143-50.

11. Huskamp HA, Busch AB, Uscher-Pines L, Barnett ML, Riedel L, Mehrotra A. Treatment of opioid use disorder among commercially insured patients in the context of the COVID-19 pandemic. JAMA. 2020;324:2440-2.

12. Office of National Drug Control Policy. National Drug Control Strategy: National Treatment Plan for Substance Use Disorder 2020. Washington, DC: Executive Office of the President of the United States; 2020. https://www.opioidlibrary.org/ wp-content/uploads/2020/02/2020-NDCS-Treatment-Plan.pdf. Accessed 13 Dec 2020.

13. Centers for Medicare and Medicaid Services. Information on medicare telehealth. US Department of Health and Human Services; 2018. https://www.cms.gov/AboutCMS/Agency-Information/OMH/Downloads/Information-on-Medicare-TelehealthReport.pdf?utm_source $=$ Telehealth + Enthusiasts\&utm_campaign $=218 \mathrm{~d} 4 \mathrm{f} 1 \mathrm{f} 30$ EMAIL_CAMPAIGN_2018_11_26_11_35\&utm_medium=email\&utm_term=0_ae00b0e89a-218d4f1f30-353223937. Accessed 10 Oct 2020.

14. Mehrotra $A$, Jena $A B$, Busch $A B$, Souza J, Uscher-Pines $L$, Landon $B E$. Utilization of telemedicine among rural Medicare beneficiaries. JAMA. 2016;35:2015-6.

15. Anderson $M$, Kumar $M$. Digital divide persists even as lower-income Americans make gains in tech adoption. Pew Research Center; 2019. https://www. pewresearch.org/fact-tank/2019/05/07/digital-divide-persists-even-as-lowerincome-americans-make-gains-in-tech-adoption/. Accessed 24 July 2020.

16. Anderson M, Perrin A. Disabled Americans are less likely to use technology. Pew Research Center; 2017. https://www.pewresearch.org/fact-tank/2017/04/ 07/disabled-americans-are-less-likely-to-use-technology/. Accessed 20 July 2020.
17. Perrin A, Turner E. Smartphones help Blacks, Hispanics bridge some-but not alldigital gaps with Whites. Pew Research Center; 2019 https://pewrsr.ch/2Z1PKPf. Accessed 20 Aug 2020.

18. Ramsetty A, Adams C. Impact of the digital divide in the age of COVID-19. J Am Med Inform Assoc. 2020;27:1147-8.

19. Cowan KE, McKean AJ, Gentry MT, Hilty DM. Barriers to use of telepsychiatry: clinicians as gatekeepers. Mayo Clin Proc. 2019;94:2510-23.

20. Drago A, Winding TN, Antypa N. Videoconferencing in psychiatry, a meta-analysis of assessment and treatment. Eur Psychiatry. 2016;36:29-37.

21. Hubley S, Lynch SB, Schneck C, Thomas M, Shore J. Review of key telepyschiatry outcomes. World J Psychiatry. 2016;6:269-82.

22. Lin LA, Casteel D, Shigekawa E, Weyrich MS, Roby DH, McMenamin SB. Telemedicine-delivered treatment interventions for substance use disorders: a systematic review. J Subst Abus Treat. 2019;101:38-49.

23. Santesteban-Echarri O, Piskulic D, Nyman RK, Addington J. Telehealth interventions for schizophrenia-spectrum disorders and clinical high-risk for psychosis individuals: a scoping review. J Telemed Telecare. 2020;26:14-20.

24. Health Resources and Services Administration/National Center for Health Workforce Analysis; Substance Abuse and Mental Health Services Administration/Office of Policy, Planning, and Innovation. National Projections of Supply and Demand for Behavioral Health Practitioners: 2013-2025. Rockville, Maryland. 2015.

25. Bishop TF, Press MJ, Keyhani S, Pincus HA. Acceptance of insurance by psychiatrists and the implications for access to mental health care. JAMA Psychiatry. 2014;71:181.

26. Naslund JA, Shidhaye R, Patel V. Digital technology for building capacity of nonspecialist health workers for task sharing and scaling up mental health care globally. Harv Rev Psychiatry. 2019;27:181-92.

27. Unützer J, Carlo AD, Collins PY. Leveraging collaborative care to improve access to mental health care on a global scale. World Psychiatry. 2020;19:36-37.

28. Substance Abuse and Mental Health Services Administration. Key substance use and mental health indicators in the United States: results from the 2019 National Survey on Drug Use and Health. Rockville, MD: Center for Behavioral Health Statistics and Quality, Substance Abuse and Mental Health Services Administration; 2020.

29. National Center for Quality Assurance. Follow-up after hospitalization for mental illness. https://www.ncqa.org/hedis/measures/follow-up-after-hospitalization-formental-illness/. Accessed 8 Oct 2020 